\title{
1 Transcriptomic analysis of quinoa reveals a group of germin-like proteins induced by
}

\section{Trichoderma}

3 Oscar M. Rollano-Peñaloza, Instituto de Investigaciones en Productos Naturales, Universidad Mayor de San

4 Andrés, Campus Universitario Cota Cota c 27, La Paz, Bolivia; and Department of Biology, Lund University,

5 Sölvegatan 35B, SE-223 62 Lund, Sweden

6 oscar_miguel.rollano_penaloza@biol.lu.se and bios.mrp@gmail.com

7 Patricia A. Mollinedo, Instituto de Investigaciones en Productos Naturales, Universidad Mayor de San Andrés,

8 Campus Universitario Cota Cota c 27, La Paz, Bolivia

9 pattymollinedo@gmail.com

10 Susanne Widell, Department of Biology, Lund University, Sölvegatan 35B, SE-223 62 Lund, Sweden

11 susanne.widell@biol.lu.se

12 Allan G. Rasmusson, Department of Biology, Lund University, Sölvegatan 35B, SE-223 62 Lund, Sweden

$13 \quad$ Allan.rasmusson@biol.lu.se

14

15 Corresponding author: Allan G. Rasmusson 


\section{Abstract}

Symbiotic strains of fungi in the genus Trichoderma affect growth and pathogen resistance of many plant species, but the interaction is not known in molecular detail. Here we describe the transcriptomic response of two cultivars of the crop Chenopodium quinoa to axenic co-cultivation with Trichoderma harzianum BOL-12 and Trichoderma afroharzianum T22. The response of $C$. quinoa roots to BOL-12 and T22 in the early phases of interaction was studied by RNA sequencing and RT-qPCR verification. Interaction with the two fungal strains induced partially overlapping gene expression responses. Comparing the two plant genotypes, a broad spectrum of putative quinoa defense genes were found activated in the cultivar Kurmi but not in the Real cultivar. In cultivar Kurmi, relatively small effects were observed for classical pathogen response pathways but instead a C. quinoa-specific clade of germin-like genes were activated. Germin-like genes were found to be more rapidly induced in cultivar Kurmi as compared to Real. The same germin-like genes were found to also be upregulated systemically in the leaves. No strong correlation was observed between any of the known hormone-mediated defense response pathways and any of the quinoa-Trichoderma interactions. The differences in responses are relevant for the capabilities of applying Trichoderma agents for crop protection of different cultivars of $C$. quinoa.

\section{Background}

Trichoderma is a genus of ascomycete fungi widely studied for its versatile interactions with other organisms. Trichoderma are also symbionts with plants and can promote plant growth by several, yet so far only partially known mechanisms. Strains of several symbiotic species in the Trichoderma harzianum species complex (e.g. substantially improve yields of several species of crops. The strain T22 can enrich the soil nutrient availability to plants (2), and several species of Trichoderma have also been shown to enhance plant growth through volatile compound emission $(3,4)$ and stimulate plant systemic defense responses $(5,6)$. Nevertheless, plants do not always benefit from these interactions as described for some maize cultivar in field trials and lab experiments (7). Plant growth inhibition by T. harzianum has also been observed in axenic co-cultures with quinoa seedlings (8).

41 Quinoa (Chenopodium quinoa Willd.) is an emerging crop of great interest due to its nutritional values (9) and its 42 resistance to hostile environmental conditions, especially salinity and drought $(10,11)$. Quinoa seeds are gluten43 free, contain all essential amino acids and its composition (vitamins, antioxidants, fatty acids and minerals) is 
highly suitable for human nutrition (12). Quinoa has a high genetic diversity, e.g. more than 4,000 accessions have been registered by the Food and Agriculture Organization (13). The high genetic diversity of cultivars is the result of many years of selection by the indigenous people of the Andean Altiplano, where quinoa may have been domesticated 7,000 years ago by pre-Columbian cultures (14).

Quinoa agricultural yields can be boosted by Trichoderma application, as previously described (15). However, the outcome of plant-Trichoderma interactions is not always beneficial. Plant genotype-specific growth inhibition by commercially available Trichoderma strains have been reported for lentils (16), tomato (17) and maize (7). Thus, the incompatibility of particular plants with particular biocontrol strains can lead to undesired agricultural losses. Therefore, there is a need to understand the genotype-specific interaction mechanisms that determine whether plant growth is promoted or inhibited by biocontrol agents like T22. plant growth inhibition when treated with $T$. harzianum BOL-12 and T. afroharzianum T22 in axenic co-cultures. The response of quinoa to BOL-12 and T22 in the early phases of interaction was studied by transcriptomic analysis and RT-qPCR verification. Overall, we observed that upon interaction with the two fungal strains, a broad spectrum of putative quinoa defense genes were activated in Kurmi but not in the Real cultivar.

\section{Methods}

\section{Biological materials}

61 Seeds of quinoa (Chenopodium quinoa Willd.) cultivars Maniqueña Real (Real) and Kurmi were kindly supplied by PROINPA (Quipaquipani, Bolivia). Trichoderma afroharzianum, Rifai, T22, anamorph ATCC 20847 (1) was purchased from the American Type Culture Collection (Manassas, VA, USA). Trichoderma harzianum BOL-

64 12QD (BOL-12) was isolated and provided by the Instituto de Investigaciones Farmaco-bioquímicas (IIFB-

65 UMSA, La Paz, Bolivia).

\section{Fungal growth}

T22 and BOL-12 were maintained on potato dextrose agar (BD-Difco, Detroit, USA) at $25^{\circ} \mathrm{C}$. To isolate 
twice with sterile $\mathrm{ddH}_{2} \mathrm{O}$ and pelleted at $3700 \mathrm{~g}$ for $5 \mathrm{~min}$ at $4{ }^{\circ} \mathrm{C}$ in an Allegra X-12R centrifuge (Beckman, Brea,

71 CA, USA). Spores were resuspended in sterile $\mathrm{ddH}_{2} \mathrm{O}$ and kept at $4^{\circ} \mathrm{C}$ until experiments.

72 Germination of T22 and BOL-12 spores for C. quinoa treatment was performed as described by Yedidia,

73 Benhamou (18) using $15 \mathrm{ml}$ tubes shaken at $200 \mathrm{rpm}$ for $18 \mathrm{~h}$. The germinated spore suspension was washed twice

74 by centrifugation as described above and finally resuspended in sterile $\mathrm{ddH}_{2} \mathrm{O}$. The final spore concentration was adjusted to be 1 germinated spore/ $\mu$ and verified by colony forming unit (CFU) counts in potato dextrose agar Petri dishes.

Seeds of C. quinoa were surface-sterilized by soaking in commercial bleach $(\mathrm{NaClO} ; 27 \mathrm{~g} / \mathrm{kg}$ ) for $20 \mathrm{~min}$., in Petri dishes and incubated in darkness at $24^{\circ} \mathrm{C}$ for 14 hours (8).

\section{Co-culture of quinoa and T. harzianum in Petri dishes}

Five germinated axenic seedlings of each cultivar Kurmi and Real with similar root length were aligned on a straight line on 12x12 cm square Petri dishes containing 0.1X Murashige and Skoog Basal Salts Mixture (MS; Duchefa, Haarlem, The Netherlands), supplemented with $8 \mathrm{~g} / \mathrm{L}$ agar. The Petri dishes were then tilted $45^{\circ}$ during growth with the agar/air interface facing upwards and seedlings having the roots pointing towards the bottom part of the Petri dish. The seedlings were incubated at $24^{\circ} \mathrm{C}$ for 4 hours before treatment with T22 or BOL-12. After treatment, the seedlings were incubated at $24^{\circ} \mathrm{C}$ in a $16 \mathrm{~h}$ light $/ 8 \mathrm{~h}$ dark photoperiod. Co-cultivation was done under fluorescent lights (Polylux XLr 30W, GE, Budapest, Hungary) at $50 \mu \mathrm{mol} \mathrm{m}^{-2} \mathrm{~s}^{-1}$ for 12 and 36 hours.

\section{Seedling growth analysis}

Hypocotyl length was analyzed from images taken with a Digital Camera Canon EOS Rebel T3. Measurements from the photographs were done with the segmented line tool of ImageJ 1.49 (19).

\section{Sample collection and RNA extraction}


97

98

99

100

101

102

103

104

105

106

107

108

109

110

111

112

113

114

115

116

117

118

119

120

121

122

123

124

pooled into one replicate on pre-weighed aluminum foil envelopes. The envelopes were weighed on a precision

balance and shock-frozen in liquid nitrogen. Frozen samples were either processed immediately or stored at $-80^{\circ} \mathrm{C}$ until RNA extraction. Roots and shoots were pooled separately.

Total RNA was extracted using the RNeasy Plant Mini Kit (Qiagen, Valencia, CA, USA), with the following modification: Root tissue samples preserved in liquid nitrogen were placed in a precooled mortar containing liquid nitrogen followed by thoroughly grinding without letting the samples thaw. Then $450 \mu \mathrm{L}$ of Buffer RLT (Qiagen, Valencia, CA, USA) supplemented with B-mercaptoethanol (1\%) was added. Grinding continued until samples thawed and were transferred to a $1.5 \mathrm{ml}$ microcentrifuge tube. The rest of the procedure was followed according to Qiagen instructions. Total RNA quantity and quality was determined with a NanoDrop spectrophotometer. DNase treatment was performed with the DNA-free kit (Ambion, Carlsbad, CA, USA), following the instructions of the manufacturer. The integrity and quality of the RNA was determined as follows: 500 ng. of DNase-treated RNA were dissolved in $8 \mu \mathrm{l}$ of sterile water and split it in two aliquots, one placed on ice and the other placed at $37^{\circ}$, both for 20 minutes, immediately $2 \mu$ of loading buffer was added to each sample and together were loaded to an agarose gel (2\%) stained with ethidium bromide. The gel was run at $80 \mathrm{~V}$ for $30 \mathrm{~min}$ and visualized in an UV-transilluminator. Samples with sharp $18 \mathrm{~S}$ and $28 \mathrm{~S}$ rRNA and showing no evidence of degradation were retained.

\section{RNA-seq library construction and sequencing}

Total RNA treated with DNase was sent to IGA technology services (IGA, Udine, Italy; http://www.igatechnology.com) for poly(A) ${ }^{+}$mRNA purification, strand-specific cDNA synthesis, library construction (Truseq stranded mRNA-seq) and sequencing using a HiSeq2500 (Illumina Inc., San Diego, CA, USA) in paired-end mode with a read length of $125 \mathrm{bp}$. Raw sequences have been deposited at the National Center of Biotechnology Information NCBI under the Sequence Read Archive (SRA): SUB9370528.

\section{Transcriptomic analysis}

RNA-seq reads were checked for quality by FastQC (v.0.9.0) and mapped on the quinoa genome "Kd" (Yasui et al., 2016) and to the QQ74 coastal genome (20) by Tophat2 (v.2.2.9). Transcript abundances were assessed with HTSeq (v.0.9.1) with "intersection-nonempty" mode. Genes that had a minimum of 1 read mapped in each of the samples considered for analysis were included. Gene expression levels were measured as counts per million (CPM) (21). Library size normalization was performed using the trimmed mean of $M$-values (TMM) within the R package 
125

126

127

128

129

130

131

132

133

134

135

136

137

138

139

140

141

142

143

144

145

146

147

148

149

150

edgeR (v.3.14.0) (22, 23). Differential gene expression analysis (treated vs mock-treated) was performed using edgeR with TMM normalized libraries (21) with a false discovery rate (FDR) of $5 \%(\mathrm{q}<0.05)$ (24).

\section{Functional annotation of differentially expressed genes}

Gene ontology (GO) term enrichment for sets of differentially expressed genes were estimated with Argot2 through sequence function prediction (25). Singular enrichment analysis (SEA) for biological processes was performed with AgriGO v2.0 (26). The statistical test for SEA was Fisher's exact test and for false discovery rate the Yekutieli method was applied (27).

\section{cDNA synthesis and gene expression by qRT-PCR analysis}

Synthesis of cDNA was carried out with $500 \mathrm{ng}$ of total RNA added to each $20 \mu$ reaction of the RevertAid H Minus Reverse Transcription Kit (Thermo Scientific). The cDNA samples were stored at $-20^{\circ} \mathrm{C}$ for downstream analysis. qRT-PCR of plant RNA was performed in a CFX384 Touch Real-Time PCR system (Bio-Rad, Hercules, CA, United States) using Maxima SYBR Green qPCR Master Mix (Thermo Scientific) supplemented with 0.25 $\mu \mathrm{M}$ of each specific primer and $10 \mathrm{ng}$ of cDNA as template in a total volume of $10 \mu \mathrm{l} /$ reaction. The PCR program had the following conditions: 1 cycle of: $95^{\circ} \mathrm{C}, 20 \mathrm{~s} ; 30$ cycles of: $\left(95^{\circ} \mathrm{C}, 15 \mathrm{~s} ; 60^{\circ} \mathrm{C}, 20 \mathrm{~s} ; 72{ }^{\circ} \mathrm{C}, 20 \mathrm{~s}\right)$. The specificity of each PCR amplification was determined by melting curve analysis and by analysis in $2 \%$ agarose gels. The primer sequences can be found in Table S7. The relative transcript expression was calculated by the Pfaffl algorithm using, $C q A C T 2 A$ and $C q M O N 1$, as reference genes. Ten-fold dilutions of cDNA template were used to determine the amplification efficiency for each gene (28).

Primer pairs were designed using Perlprimer (29) so that one of the primers in each pair spanned an exon-exon border, and the primer pairs were additionally checked using Netprimer (premierbiosoft.com) to avoid primerprimer interactions.

\section{Protein evolution}

Protein alignments were made using Muscle (30). Aminoacid substitution models were evaluated by MEGA X (31). The protein evolutionary tree was performed by maximum likelihood using LG model (32) with gamma distribution $(\mathrm{LG}+\mathrm{G})$ and $95 \%$ limit for partial gaps. Total positions in the final dataset were 191. Bootstrap testing was conducted with 1000 replicates. 


\section{$151 \quad$ Results}

\section{Trichoderma BOL-12 and T22 inhibit the growth of $\boldsymbol{C}$. quinoa seedlings under certain axenic conditions}

153 Previously we have observed that quinoa growth was inhibited by two Trichoderma strains under axenic conditions

154 (8). Therefore, we decided to investigate the axenic co-culture of quinoa with T22 and BOL-12 by gene expression

155 analysis to detect the molecular signaling possibly responsible of the $C$. quinoa growth inhibition. Briefly, quinoa

156 seedlings of cultivars Kurmi and Real were grown for $18 \mathrm{~h}$ in square petri dishes on $0.1 \mathrm{x}$ MS and $0.8 \%$ agar and

157 co-cultivated with T22 or BOL-12 for 12 and 36 hours. The studied Trichoderma strains did not have any

158 measurable effect on the growth of $C$. quinoa seedlings during this short time of co-cultivation. Thus, the growth

159 pattern was consistent with previously reported.

160 Transcriptome sequencing of $C$. quinoa in axenic co-culture with Trichoderma

161 RNA samples from quinoa roots treated with Trichoderma for 12 and 36 hours were collected. RNA samples at

16212 hours post inoculation (hpi) were analysed through RNA-seq and RNA samples at 36 hpi were evaluated

163 through posterior qRT-PCR. For the transcriptomic analysis three biological replicates of each treatment were

164 sequenced in paired-end mode. The final number of reads that passed the quality control varied between 10.2 and

16523.1 million paired-end reads of $125 \mathrm{bp}$ per sample (Table 1). Reads were mapped to the draft quinoa genome of

166 cultivar Kd as well as to the chromosome-level assembly of the quinoa genome cultivar QQ74 (Table 1). On

167 average, the proportion of mapped reads was substantially increased when reads were mapped to the QQ74 quinoa

168 genome (93.9\%), as compared to the draft Kd quinoa genome (71.8\%). Therefore, all downstream analyses were

169 performed with data mapped to the QQ74 genome.

\section{Differential gene expression in quinoa in response to Trichoderma treatment}

171 The differential gene expression analysis considered only reads that mapped to unique locations in the QQ74

172 genome. The average number of reads that were mapped to unique locations in the QQ74 genome was 89.8\%

173 (Table 1). The remaining reads (10.2\%) producing multiple alignments were discarded. Further, only quinoa genes

174 with at least one read in each of the samples analysed were considered (Table 2). Gene expression levels were

175 measured as counts per million (CPM) . CPM were TMM-normalized in order to compensate for library size

176 differences. Differential gene expression analysis comparing mock-treated samples with samples treated with

177 Trichoderma was performed with edgeR. 
178 Quinoa roots in general induced more genes than they repressed upon interaction with Trichoderma, with the

179 exception of Kurmi interacting with T22 where more genes were repressed than induced (Table 2). Kurmi treated

180 with T22 showed 16 times more differentially expressed genes than in the treatment with BOL-12. Similarly,

181 quinoa cv. Real treated with T22, compared to the mock-controls, had 5.5 times more differentially expressed

182 genes than Kurmi in the treatment with BOL-12 (Table 2).

183 Regarding communal effects by both Trichoderma strains, we observed more genes differentially expressed in $\mathrm{cv}$.

184 Real (141 genes) than in cv. Kurmi (75 genes) (Tables S1-3). Among the quinoa genes up- or downregulated under

185 one or several conditions, only 19 were communally differentially expressed in all experimental combinations,

186 and all were induced (Figure 1, Table 3). That is, they were significantly induced during the interaction of each

187 quinoa cultivar with each Trichoderma strain. The group of 19 differentially expressed genes were not significantly

188 associated with any functional GO term upon analysis by SEA. However, the GO analysis suggests that 13 of the

18919 gene products are localized outside the cytoplasm. This indicates activity at the plasma membrane, the cell wall

190 and the extracellular compartment, indicating functions relating to interactions with external stimuli (Table 3).

\section{Quinoa genes differentially expressed unique to each cultivar}

192 We decided to analyze genes that were induced by Trichoderma and were uniquely expressed in each cultivar.

193 The Kurmi cultivar upon interaction with either BOL-12 or T22, expressed 75 genes that were communally

194 differentially expressed (DE) but were not differentially expressed upon either Trichoderma interaction in cv. Real

195 (Figure 1 and 2, Table S1). The expression profiles of these genes were clustered by Euclidean distance and are

196 shown in Figure 2. From the 75 DE genes in cv. Kurmi by both strains of Trichoderma, 59 genes were induced

197 (Table S1), whereas 16 DE genes were repressed (Table S2). The 75 DE genes expressed in cv. Kurmi are

198 expressed in cv. Real but are not responsive to the treatment with either of the Trichoderma strains (Figure 2).

199 Analysis of the 59 significantly induced genes revealed that 17 genes ( $C q G L P s)$ are highly expressed and share a

200 high protein sequence identity (90\%). These genes encode proteins that belong to the germin-like protein family

201 (GLPs) (Figure 2; Table S1). Further, several genes involved in flavonoid biosynthesis were specifically

202 responsive in Kurmi. We identified 9 genes whose orthologs in Arabidopsis thaliana are described to be involved

203 in the flavonoid biosynthesis pathway. These differentially expressed genes are orthologs to four out of five

204 enzyme-coding genes necessary for production of flavonol glycosides from naringenin, also known as chalcone

205 (33) (Figure 2, Table S1). 
The Real cultivar had 141 genes differentially expressed common to both Trichoderma strains tested (Figure 1,

Table S3). The cv. Real response to both Trichoderma strains showed mostly activation of transcription factors and enzymes without a significant match to a known pathway. Among the genes that were differentially expressed there are 4 ethylene-responsive transcription factors, 9 probable WRKY transcription factors and 3 chitinases

\section{0 (Table S3).}

211 Genes differentially expressed related to biotic interactions were observed in mayor proportions in quinoa cv.

212 Kurmi than Real. Therefore, the focus of this study was on the response of the Kurmi cultivar. Functional

\section{3 annotation of differentially expressed genes}

214 To assess the function of the differentially expressed genes we annotated the differentially expressed genes of all 215 combinations with Gene Ontology (GO) terms for biological processes. The quinoa genome has 44776 annotated 216 genes (20) but the annotation with Argot only assigned GO terms to $50.5 \%$ of the genes (i.e. 22650 genes 217 annotated with GO terms). Despite the low percentage of GO terms assigned, GO annotation for the biological 218 process category in Kurmi plants treated with BOL-12 revealed defense response (GO:0006952) and response to 219 biotic stimulus (GO:0009607) as the main and only processes associated to Trichoderma BOL-12 treatment (Table S4). In contrast, the interaction between Kurmi and T22 did not show any significant GO term for biological processes.

Quinoa plants of the Real cultivar had more genes associated to GO terms than Kurmi. However, no specific association to a cluster of similar GO terms were observed (Table S4). Specifically, Real treated with T22 showed 38 genes that were annotated to response to stress (GO:0006950) and 6 genes that were annotated to chitin catabolic processes (GO:0006032) and associated redundant GO terms (Table S4). Further, Real treated with BOL12 did not show any GO terms directly associated to defense response or response to stress, yet highest significance was observed to GO terms for cell wall related processes (Table S4). Nonetheless, in the interaction between Real and each strain of Trichoderma we observed several genes related to defense being commonly activated. Among them WRKY transcription factors (9 differentially expressed genes), ethylene-responsive genes (4 differentially expressed genes) and chitinases (3 differentially expressed genes) (Table S3).

\section{Validation of RNA-seq with qRT-PCR}

232 Quinoa root transcriptomes have not previously been analysed. We therefore validated the gene expression data 233 obtained by RNA-seq by performing qRT-PCR for 10 selected genes, including induced, repressed and stably 
235 showed a strong correlation $\left(\mathrm{R}^{2}\right)$ of 0.848 . The correlation was higher when the different quinoa-Trichoderma

236 interaction pairs were assessed independently (Table S5).

\section{Changes in root gene expression at $36 \mathrm{hpi}$}

238 Time changes in the expression of quinoa genes by Trichoderma treatment were assessed by qRT-PCR at 36 hpi.

239 We followed time-dependent changes in two highly induced genes ( $C q G L P 1$ and $C q G L P 10)$ representing the GLP

240 family and one gene that was induced in all quinoa-Trichoderma interactions (CqHSP83). The gene expression of

$241 C q G L P 1$ and $C q G L P 10$ was reduced at 36 hpi compared to 12 hpi in the Kurmi cultivar but its expression was

242 still higher than the mock-treatment. In contrast, the gene expression of CqGLP1 and CqGLP10 in the Real cultivar

243 was higher at 36 hpi than at 12 hpi, being statistically significant in the Real - BOL-12 interaction (Figure 4). The

244 CqHSP83 gene maintained its level of gene expression between 12 hpi and 36 hpi by application of T22 in both

245 cultivars. In contrast, the application of BOL-12 to both cultivars downregulated CqHSP83 gene expression at 36

246 hpi as compared to 12 hpi. However, the downregulation was only significant in the Kurmi cultivar (Figure 4).

247 Overall, the results indicate that the induction of the analysed genes is slower in cv. Real than in cv. Kurmi.

\section{Shoot gene expression}

249 We investigated changes in the quinoa shoot gene expression $36 \mathrm{~h}$ after Trichoderma treatment at the root neck

250 (Figure 5). Ten out of 12 genes investigated were also expressed in the shoots, CqPER39 and CqPR1C gene 251 expression was not detected at the shoots in any of the combinations studied (Table S6). Trichoderma-induced 252 gene expression changes at the shoots (Figure 5) showed a generally similar pattern of gene expression as observed 253 in the roots at 36 hpi (Figure 4). CqGLP1 and CqGLP10 are significantly expressed in both cultivars upon 254 interaction with BOL-12 but not with T22. Likewise, CqHSP83 is significantly expressed in both cultivars when 255 interacting with T22 but not when interacting with BOL-12 (Figure 5). The other genes did not show a significant 256 correlation in the Shoot-root expression in any of the quinoa-Trichoderma interactions studied (Table S6).

\section{Evolutionary analysis of the germin-like proteins}

258 Plant germins were first investigated and have been characterised in most functional detail in cereals (34). To 259 investigate the coincidental induction of germin-like proteins in cv. Kurmi (Table S1), we carried out BLAST 260 searches to identify all germin and germin-like homologues in C. quinoa, Beta vulgaris, A. thaliana and Hordeum 261 vulgare and performed alignments and evolutionary analyses. We found that 16 of the17 quinoa GLPs induced by 
Trichoderma (highlighted in green) in cv. Kurmi belong to a single (98\% bootstrap) C. quinoa-specific clade of 29 homologues (Figure 6 and Table S8). The remaining GLP induced by Trichoderma (CqGLP20) groups in an unresolved putative clade, which contains four quinoa GLPs and one sugarbeet GLP (Figure 6). The relation of the quinoa-specific clade to homologues in other species, including the closest relative $B$. vulgaris, was not resolved, whereas other groups of quinoa germin-like proteins were significantly associated with specific homologues in B. vulgaris. Species-specific gene groups were also observed for B. vulgaris and A. thaliana. The result suggests that recent expansions of gene groups have occurred independently in the amaranth family species C. quinoa and B. vulgaris.

\section{Discussion}

The outcome of plant-Trichoderma interactions with respect to both growth and physiological changes has been shown to be genotype-specific regarding both the plant and the Trichoderma biomaterial $(5,17)$. Here, we have observed a small set of quinoa genes being responsive in all combinations of Trichoderma strains and quinoa cultivars studied. However, we have found many more genes that are differentially expressed by a specific quinoa cultivar in response to either or both of two Trichoderma strains (Figure 1). Nonetheless, the outcome of the interaction of Trichoderma on plant growth in axenic co-cultures is negative for plants, similarly for both quinoa cultivars and consistent with previous observations (8).

The set of 19 genes that showed significant responses in all cultivar-strain combinations mainly include genes connected to biotic stress response and cell wall modification (Table 3). Orthologs of these genes are known to be involved in defense response. For example, the polygalacturonase inhibitor protein AtPGIP1 (AT5G06860) in $A$. thaliana is thought to inhibit cell wall pectin degrading enzymes, commonly produced by fungal pathogens (35). Xyloglucan endotransglucosylase/hydrolases are cell wall repairing enzymes, many of which are induced by fungal infection (36). Further, two highly similar (protein sequence identity of 94,3\%) heat-shock proteins (CqHSP83A and $C q H S P 83 B$ ) annotated to be involved in general stress responses (GO:0006950) were upregulated in all quinoa-Trichoderma interactions. Large heat-shock proteins $(70-90 \mathrm{kDa})$ are known to be involved in plant defense response through the stabilization of protective plant proteins (37-39). The heat-shock proteins expressed by quinoa might have been induced to contribute to the stabilization of defense proteins that would prevent or counteract damages induced by Trichoderma (8). 
Several differences in the defense response patterns between the quinoa cultivars were observed. Especially, the

Kurmi cultivar that displays specific activation of several homologs to biotic stress-associated plant genes (Table

291 S1-2). In contrast, the responsive genes in cv. Real were mostly involved in general cellular processes (Table S3),

292 and to a lesser extent involving defense response genes. The defense response gene set induced in cv. Real was

293 also completely different from the one activated in Kurmi (Figure 1, Table 2 and Table S1-3). Surprisingly, in

294 neither case an obvious association to known major pathogen response pathways like jasmonic acid, salicylic acid

295 or ethylene pathways (40-42) could be observed in the GO analysis at $12 \mathrm{hpi}$. The low association of the quinoa

296 differentially expressed genes with these known pathways could, however, be caused by the relatively low level

297 of GO annotation observed for the quinoa genome.

298 The quinoa genes specifically induced in the Kurmi cultivar upon interaction with Trichoderma (Table S1)

299 resemble a set of defense response genes observed in plant-pathogenic interactions (43). Several of these induced

300 genes (chalcone synthase, chalcone isomerase, flavonol synthase, UDP glycosyl transferase and cis-zeatin O-

301 glucosyltransferase) belong to the flavonoid biosynthetic pathway (33). Flavonoids have an important role in plant

302 defense $(43,44)$. For example, some $A$. thaliana mutants lacking the UDP glycosyl transferase gene (AtUGT74F1)

303 are more susceptible to Pseudomonas syringae infection than the wild-type (45). Further, a QTL analysis for

304 pathogen resistance in soybean identified two UDP glycosyl transferase genes as the candidate genes responsible

305 for resistance to Fusarium (46). Thus, the Kurmi cultivar might be producing flavonol glycosides in order to

306 prevent damage from Trichoderma overgrowth.

307 The Kurmi cultivar specifically induced several plant defensins that belongs to the germin and GLP family (Figure

3086 and Table S1). The Trichoderma-responsive GLPs form a majority (16 genes out of 29) of a recently expanded

309 quinoa-specific clade (Figure 6, Table S8), which are thus strongly connected to Trichoderma interaction. Two of

310 the GLP genes were further tested, and were found to be also induced in leaves (Figure 5). The timing of the

311 induction further indicated that GLPs are induced in both Kurmi and Real, albeit more slowly in Real (Figure 4).

312 Especially studied in grains like barley, GLPs are plant proteins involved in defense response and characterized

313 by various enzymatic activities including oxalate oxidase (OXO), superoxide dismutase (SOD), ADP-glucose

314 pyrophosphatase/ phosphodiesterase (AGPPase) and polyphenol oxidase (PPO) $(47,48)$. A potential function of

315 germin-like proteins (GLPs) is found in its OXO and SOD activities, which may play a key role in production of

316 hydrogen peroxide $\left(\mathrm{H}_{2} \mathrm{O}_{2}\right)$ during plant defense (34). Because of a potential major importance of GLP in protecting

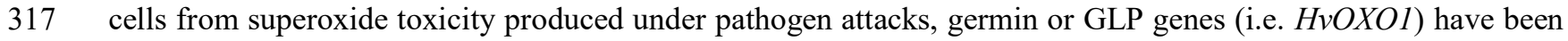


inserted into dicot plants like rapeseed or peanut to enhance its pathogen resistance (48-50). Given that several quinoa GLPs were expressed upon interaction with Trichoderma, it is very likely that these GLP defensins have an important role in the plant immune response of quinoa. Resistance to microbe attacks has been previously connected to the speed of response in different cultivars $(51,52)$. Thus, the rapid induction of a cluster of GLPs in both roots and leaves of Kurmi compared to Real (Table S2-3, Figure 4) makes these genes potential candidates for breeding to increase the tolerance to microbial attacks in quinoa plants.

324 The set of defense-related genes (peroxidases, chitinases, ERF and WRKY transcription factors) induced in quinoa 325 cv. Real upon interaction with Trichoderma (Table S3) has been observed in L. japonicus roots upon 1 hour of 326 incubation with chitin oligosaccharides (53). However, the levels of such defense-related genes returned to normal 327 after 7 hours in L. japonicus whereas in quinoa remained induced after 12 hours, possibly due to the persistance 328 of interaction with the living Trichoderma agent as compared to the transient nature of the elicitor. Similar to the L. japonicus system, the $24 \mathrm{~h}$ interaction of Trichoderma with $A$. thaliana resulted in the induction of the same

330 defense-related genes as seen here in quinoa (54). This set of genes could thus be a basal gene response of plants 331 after recognition of beneficial fungi like Trichoderma through chitin. In contrast, the Kurmi cultivar might have a 332 different set of receptors that helps the plant to perceive a possible negative effect from Trichoderma and thus 333 rapidly activate a different set of defense-related genes.

334 The plant root response to Trichoderma at transcriptomic level has been poorly studied compared to aerial parts 335 (55). Nevertheless, it has been observed that in tomato roots the recognition of Trichoderma at 24 hpi activates 336 ROS signaling, SA responses, cell wall modifications (56), JA responses and induction of plant defenses (54, 57).

337 In our study, we have observed a similar pattern for ROS signaling, cell wall modifications and induction of plant

338 defenses (Table 3, Table S1-3), confirming that the first response of root plants to beneficial fungi like 339 Trichoderma is to activate defenses. Further, our study reveals that the defense response against beneficial fungi

340 is variable between cultivars (Figure 2). The variable molecular response between cultivars to Trichoderma, could 341 help to create molecular markers of compatibility between certain plant cultivars and certain strains of

\section{Trichoderma.}

343 In conclusion, our study suggests that Trichoderma triggers a defense response in quinoa plants. Comparing the 344 defense response of two quinoa cultivars we can observe that the Kurmi cultivar mainly induced a set of genes 345 involved in plant defense. In contrast, the Real cultivar did not have a clear response because most of the changes 
mediated by Trichoderma were related to general stress and regulation of biological processes. The Kurmi cultivar

347 might have higher tolerance to microbe attacks due to the expression of genes involved in the biosynthesis of

348 flavonol glycosides and a clade of GLP-defensins unique to quinoa. These genes are thus candidates for selection

349 of quinoa cultivars with higher resistance to microbe attacks.

Figures

Kurmi-

T22

(3144)

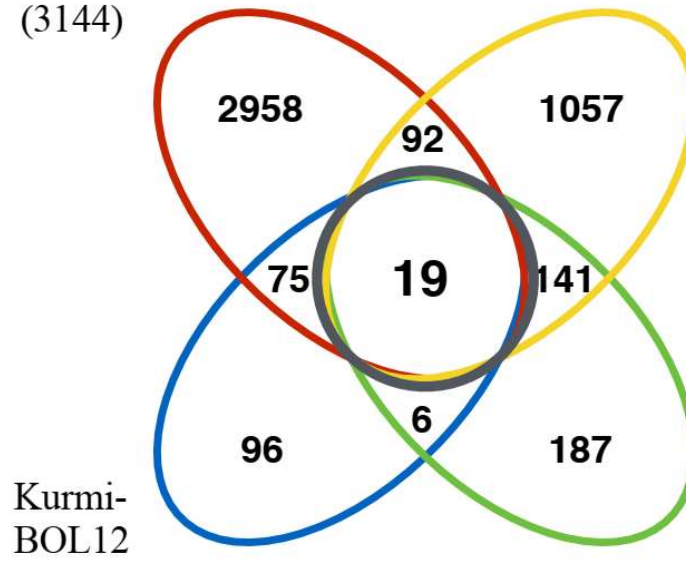

(196)
Real-

T22

(1309)

Real-

BOL12

(353)

Figure 1 Venn diagram of quinoa genes differentially expressed in response to Trichoderma. Quinoa genes

354 differentially expressed were grouped according to the cultivars and Trichoderma strains studied. The black circle

355 indicates genes differentially expressed in both quinoa cultivars by each of the Trichoderma strains tested. The

356 numbers in parenthesis indicate the number of genes differentially expressed in each of the quinoa-Trichoderma

357 interactions studied. 


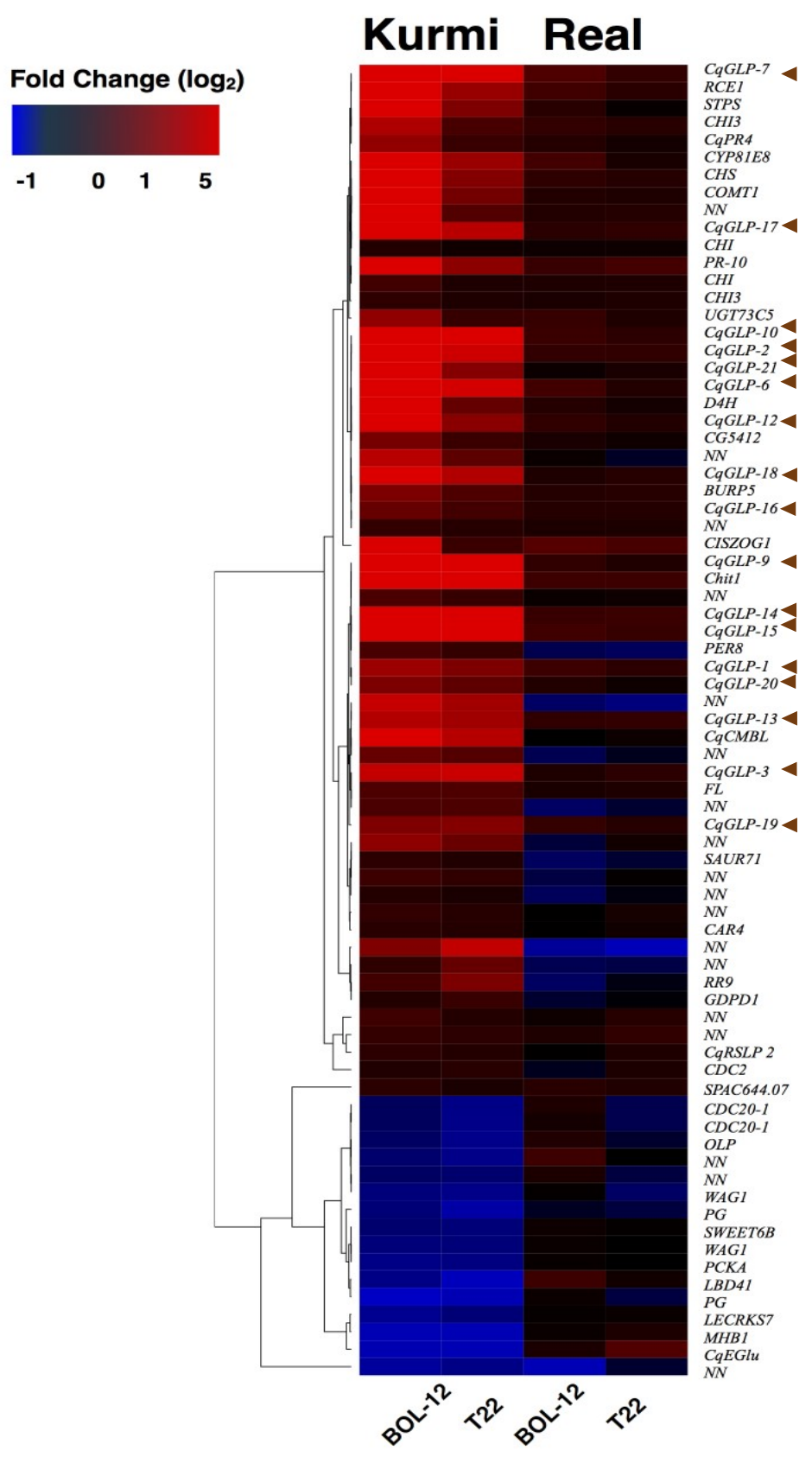

359 Figure 2 Heatmap profile of genes responsive to BOL-12 and T22 in Kurmi but not in Real. Genes

360 differentially expressed in cv. Kurmi in response to either Trichoderma strain, but not significantly responsive in

361 cv. Real, were analysed. Clustering by Euclidean distance shows the similarity in expressional change upon

362 Trichoderma treatment. Brown arrows indicate CqGLPs. 


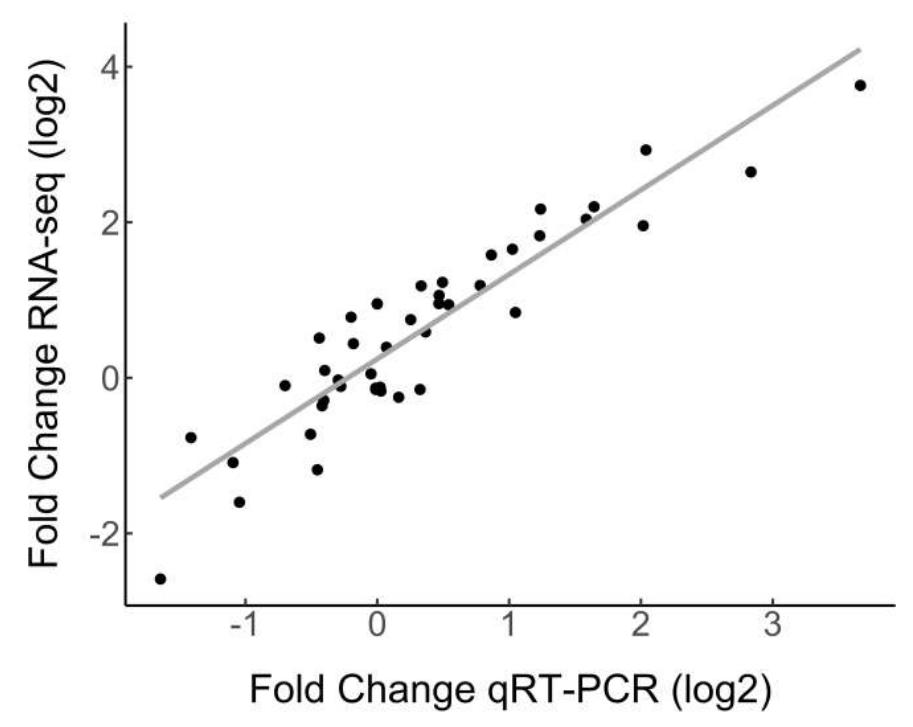

364 Figure 3 Correlation of RNA-seq and qRT-PCR gene expression data. Ten differentially expressed genes and

365 two reference genes from the RNA-seq dataset were evaluated by qRT-PCR. Gene expression by qRT-PCR was

366 normalized to the CqAct2 reference gene. Fold change was measured by comparing samples treated with

367 Trichoderma against mock- treated. The selected genes were assessed in all quinoa-Trichoderma combinations as

368 averages of triple biological replicates. The Pearson correlation coefficient between the RNA-seq and qRT-PCR

369 data was 0.921 (For data see Table S5). 


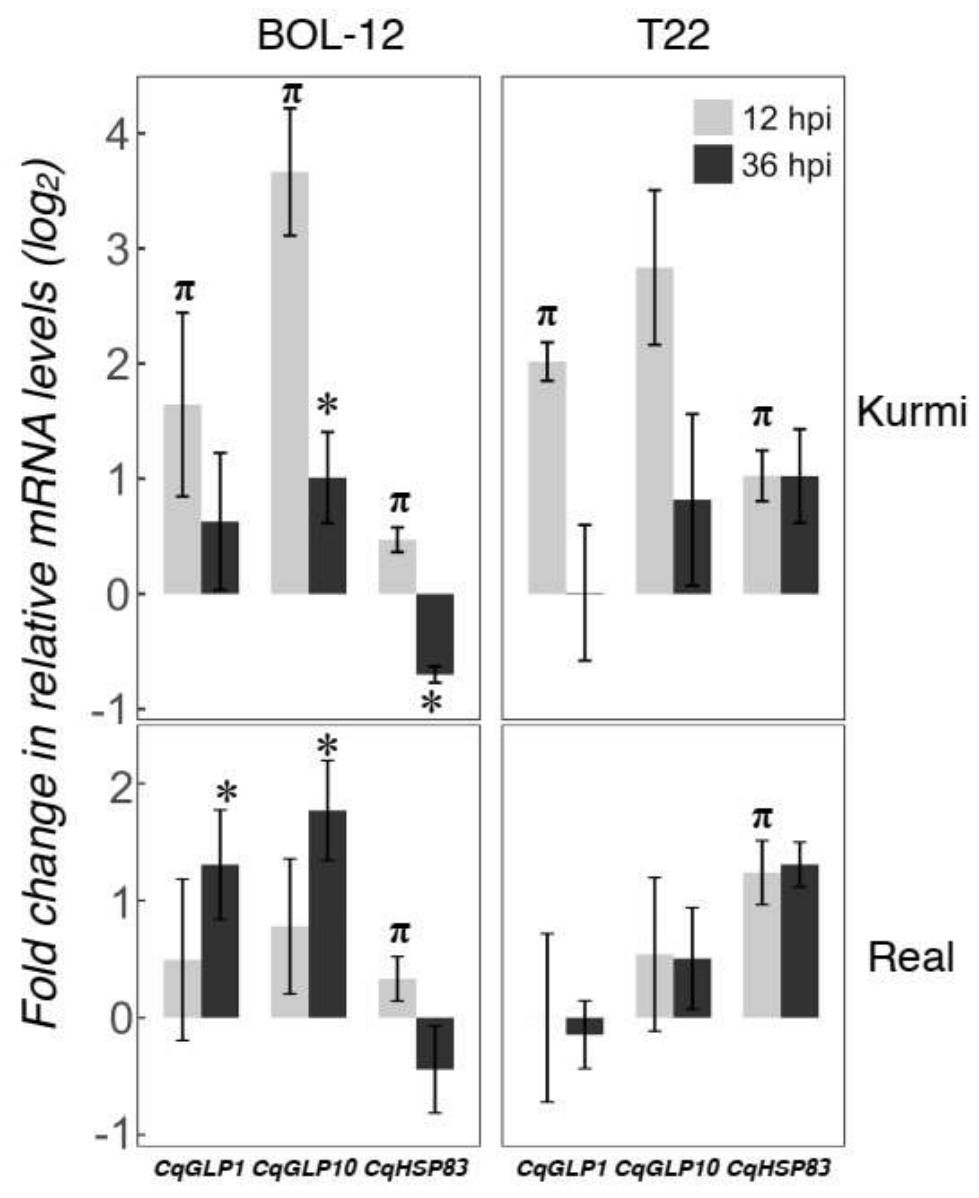

371 Figure 4 Gene expression changes at 12 and 36 hpi in representative $C q G L P s$ and $C q H S P 83$. Quinoa root

372 samples treated with Trichoderma were assessed at 36 hpi by qRT-PCR. mRNA levels were normalized to the

373 CqAct2 reference gene. Fold changes (mean $\pm \mathrm{SE}$ ) were determined by comparing samples treated with

374 Trichoderma against mock-treated ones. Asterisks denote significant changes in the gene expression as compared

375 to the control treatment by qRT-PCR at 36 hpi $(p<0.05)$. Symbol $\pi$ denotes significant changes in the gene

376 expression as compared to the control treatment, using RNA-seq $(p<0.05)$ and confirmed by qRT-PCR $(p<0.05)$

377 at 12 hpi. 


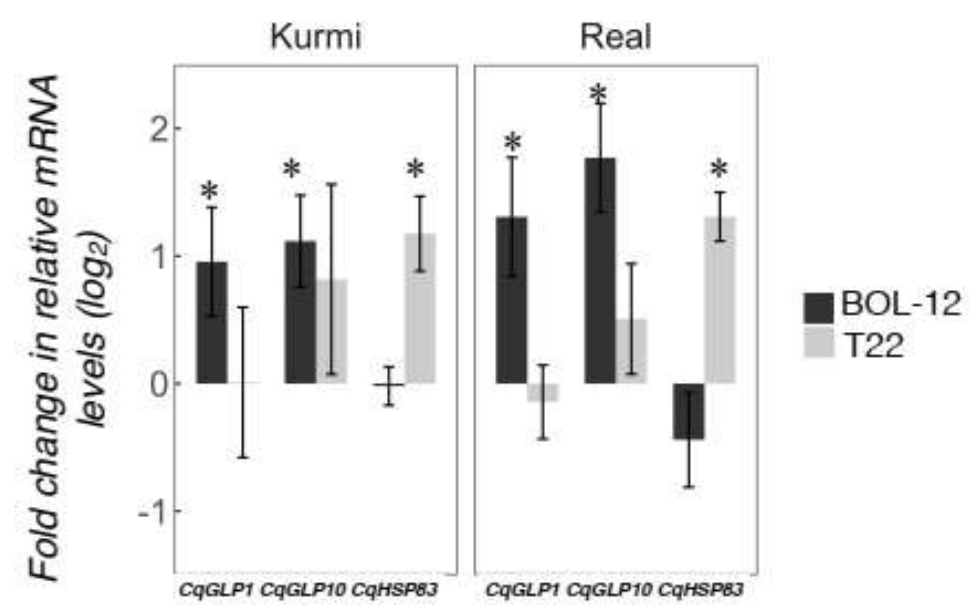

379 Figure 5 Gene expression changes in quinoa shoots after treatment of roots with Trichoderma. Quinoa shoot

380 samples were assessed by qRT-PCR $36 \mathrm{~h}$ after treatment with Trichoderma to the roots. Gene expression was

381 normalized to the CqAct2 reference gene and is shown as mean $\pm \mathrm{SE}$. Asterisks denote significant changes in the 382 gene expression as compared to the control treatment $(p<0.05)$. Two $C q G L P$ genes that were induced in Kurmi

383 roots at $12 \mathrm{hpi}$ as well as the CqHSP83 gene, which was induced in roots in all quinoa-Trichoderma interactions 384 at 12 hpi are shown. 


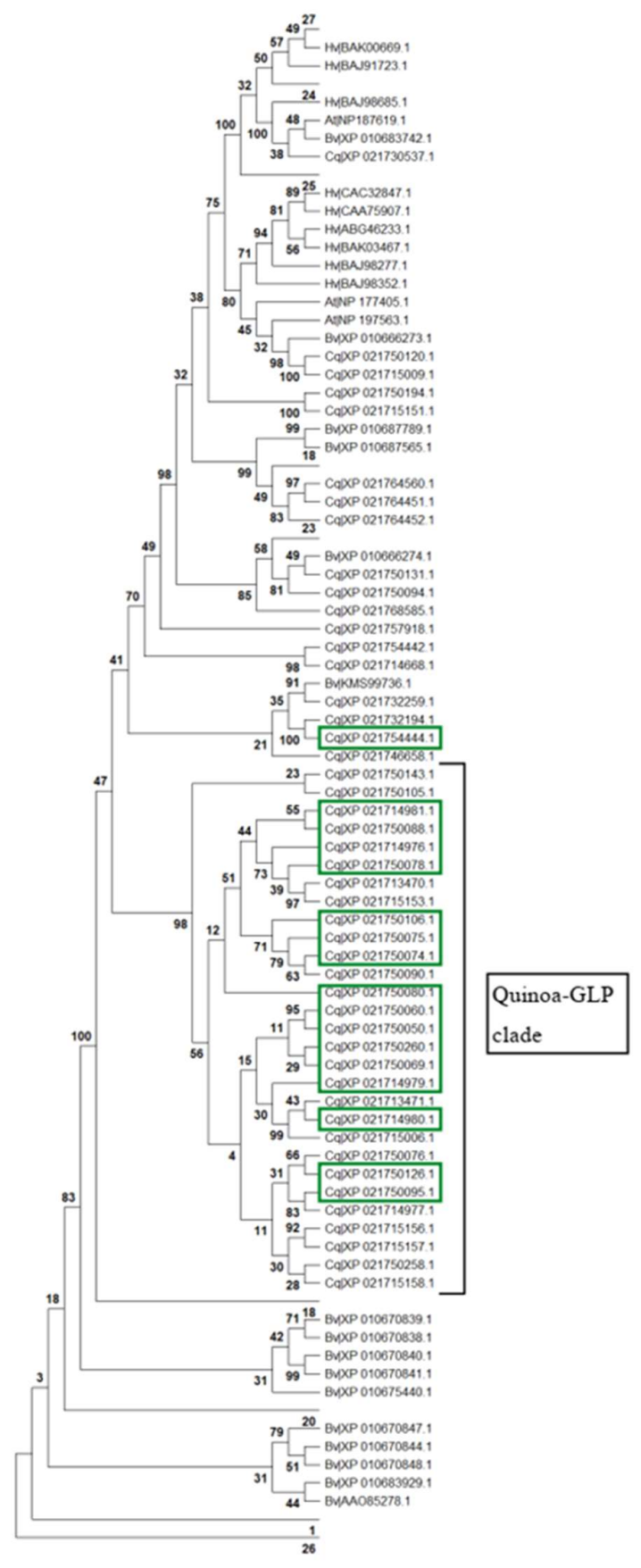

386 Figure 6. Protein evolutionary tree of germin and germin-like proteins. All identified germin-like proteins

387 found in C. quinoa (Cq), B. vulgaris (Bv), A. thaliana (At) and H. vulgare (Hv) homologues were aligned by

388 Muscle. The protein evolutionary tree was constructed by maximum likelihood using the LG $+\mathrm{G}$ model with 1000

389 iterations. Bootstrap values are given in percentage (\%). Values below 30\% are not shown except for in the

390 Trichoderma-responsive quinoa-specific GLP clade. The Trichoderma-induced homologues are marked in green. 


\section{Additional files}

Additional file 1: Table S1. Quinoa genes significantly upregulated in the cultivar Kurmi but not in Real.

393 The table shows genes that were significantly upregulated in the Kurmi cultivar when treated with either BOL-12

394 or T22. The family of GLPs is highlighted in light green. The flavonoid biosynthetic pathway is highlighted in

395 light purple. The numbers indicate averages of CPM values for each treatment $(n=3)$.

Additional file 2: Table S2. Quinoa genes significantly downregulated in the cultivar Kurmi but not in Real. are showed at the bottom for transparency.

Additional file 3: Table S3. Quinoa genes significantly up- and downregulated in the cultivar Real but not 401 in Kurmi.

402 Genes shown were significantly and consistently upregulated or downregulated in the Real cultivar when treated with either BOL-12 or T22. Highlighted in green we can observe a family of chitinases. Light purple highlights

404 WRKY genes and orange highlights ethylene-responsive genes.

For each quinoa-Trichoderma interaction, quinoa genes differentially expressed (DE) were annotated for Gene are highlighted in grey and cell wall-related terms in orange.

411 RNA from quinoa roots treated with Trichoderma or mock treated (12 hpi) were analysed by RNA-seq and qRT-

412 PCR in order to determine the correlation of expression levels. Fold change was determined by comparing samples

413 treated with each Trichoderma strain against the mock-treated control.

415 Quinoa shoot and root samples were assessed by qRT-PCR after $36 \mathrm{~h}$ treatment with Trichoderma added to the

416 roots. Gene expression was normalized to the CqAct2 reference gene. Fold change was determined by comparing 417 samples treated with Trichoderma against mock-treated. Significant differences between treatment and control is 418 highlighted in red. ND, not detected. 
420 Forward and reverse primer sequences for qRT-PCR. Primer pairs were designed using Perlprimer aiming for 421 exon-exon borders. CqAct2 were used as reference genes for normalization of the mRNA abundances and were

422 further verified by the CqMon 1 housekeeping gene.

Phytozome and NCBI codes for the germin-like proteins significantly upregulated by Trichoderma in the Kurmi cultivar. These GLPs belong to a quinoa-specific clade (Figure 6).

Additional file 9: Table S9. Differentially expressed quinoa genes upon treatment with Trichoderma.

\section{Acknowledgments}

431 We are grateful to Proinpa Institute (Quipaquipani, Bolivia) for the generous donation of quinoa seeds and the

432 Instituto de Investigaciones Farmaco-bioquímicas - UMSA (La Paz, Bolivia) for providing Trichoderma 433 harzianum BOL-12QD.

434 Genome mapping, read count and blastn computations were performed on resources provided by SNIC (Swedish

435 National Infrastructure for Computing) through Uppsala Multidisciplinary Center for Advanced Computational 436 Science (UPPMAX, Uppsala, Sweden) under Project SNIC b2015011/b2016265 along with resources provided 437 by UMSA (Universidad Mayor de Sán Andres) through Centro Nacional de Computación Avanzada para 438 Bioinformática y Genómica (CnCaBo, La Paz, Bolivia).

\section{$439 \quad$ Funding}

440 This work was funded by the Swedish International Development Agency (SIDA) in a strategic collaboration 441 between Universidad Mayor de San Andrés (UMSA) (Bolivia) and Lund University (Sweden); the Lars Hiertas 442 Minne Stiftelsen (OR) and the Jörgen Lindströms Stipendiefond (OR).

$443 \quad$ References 
444 1. Chaverri P, Branco-Rocha F, Jaklitsch W, Gazis R, Degenkolb T, Samuels GJ. Systematics of the

445 Trichoderma harzianum species complex and the re-identification of commercial biocontrol strains. Mycologia.

446 2015;107(3):558-90.

447 2. Altomare C, Norvell WA, Björkman T, Harman GE. Solubilization of Phosphates and

448 Micronutrients by the Plant-Growth-Promoting and Biocontrol Fungus Trichoderma harzianum Rifai 1295-22.

449 Applied and Environmental Microbiology. 1999;65(7):2926-33.

450 3. Jalali F, Zafari D, Salari H. Volatile organic compounds of some Trichoderma spp. increase

451 growth and induce salt tolerance in Arabidopsis thaliana. Fungal Ecology. 2017;29:67-75.

452

453

454

455

456

457

458

459

4. Lee S, Yap M, Behringer G, Hung R, Bennett JW. Volatile organic compounds emitted by

Trichoderma species mediate plant growth. Fungal Biology and Biotechnology. 2016;3(1):7.

5. Harman GE, Howell CR, Viterbo A, Chet I, Lorito M. Trichoderma species - opportunistic, avirulent plant symbionts. Nature Reviews Microbiology. 2004;2(1):43-56.

6. Mukherjee PK, Horwitz BA, Herrera-Estrella A, Schmoll M, Kenerley CM. Trichoderma

Research in the Genome Era. Annual Review of Phytopathology. 2013;51(1):105-29.

$7 . \quad H a r m a n$ GE. Overview of Mechanisms and Uses of Trichoderma spp. Phytopathology. 2006;96(2):190-4.

$460 \quad 8 . \quad$ Rollano-Peñaloza OM, Widell S, Mollinedo P, Rasmusson AG. Trichoderma harzianum T-22 and

461

462

463

464

465

466

467

468

469

470

471

472

473

474

475

476

477

478

479

BOL-12QD inhibit lateral root development of Chenopodium quinoa in axenic co-culture. Cogent Biology.

2018;4(1):1-12.

9. Vega-Gálvez A, Miranda M, Vergara J, Uribe E, Puente L, Martínez EA. Nutrition facts and functional potential of quinoa (Chenopodium quinoa Willd.), an ancient Andean grain: a review. Journal of the Science of Food and Agriculture. 2010;90(15):2541-7.

10. Bazile D, Jacobsen SE, Verniau A. The Global Expansion of Quinoa: Trends and Limits. Front Plant Sci. 2016;7:622.

11. Ruiz KB, Biondi S, Oses R, Acuña-Rodríguez IS, Antognoni F, Martinez-Mosqueira EA, et al. Quinoa biodiversity and sustainability for food security under climate change. A review. Agronomy for Sustainable Development. 2014;34(2):349-59.

12. Repo-Carrasco R, Espinoza C, Jacobsen SE. Nutritional Value and Use of the Andean Crops

Quinoa (Chenopodium quinoa) and Kañiwa (Chenopodium pallidicaule). Food Reviews International. 2003;19(1-2):179-89.

13. Zurita-Silva A, Fuentes F, Zamora P, Jacobsen S-E, Schwember AR. Breeding quinoa (Chenopodium quinoa Willd.): potential and perspectives. Molecular Breeding. 2014;34(1):13-30.

14. Dillehay TD, Rossen J, Andres TC, Williams DE. Preceramic adoption of peanut, squash, and cotton in northern Peru. Science. 2007;316(5833):1890-3.

15. Ortuño N, Castillo J, Claros M, Navia O, Angulo M, Barja D, et al. Enhancing the Sustainability of Quinoa Production and Soil Resilience by Using Bioproducts Made with Native Microorganisms. Agronomy. 2013;3(4):732-46.

480

481

482

483

484

485

486

487

488

16. Prashar P, Vandenberg A. Genotype-specific responses to the effects of commercial Trichoderma formulations in lentil (Lens culinaris ssp. culinaris) in the presence and absence of the oomycete pathogen Aphanomyces euteiches. Biocontrol Science and Technology. 2017;27(10):1123-44.

17. Tucci M, Ruocco M, De Masi L, De Palma M, Lorito M. The beneficial effect of Trichoderma spp. on tomato is modulated by the plant genotype. Molecular Plant Pathology. 2011;12(4):341-54.

18. Yedidia I, Benhamou N, Chet I. Induction of defense responses in cucumber plants (Cucumis sativus L.) by the biocontrol agent Trichoderma harzianum. Applied and Environmental Microbiology. 1999;65(3):1061-70.

489 19. Abramoff MD, Magalhães PJ, Ram SJ. Image processing with ImageJ. Biophotonics

490 international. 2004.

$49120 . \quad$ Jarvis DE, Ho YS, Lightfoot DJ, Schmöckel SM, Li B, Borm TJA, et al. The genome of 492 Chenopodium quinoa. Nature. 2017;542(7641):307-12.

493 21. Anders S, McCarthy DJ, Chen Y, Okoniewski M, Smyth GK, Huber W, et al. Count-based

494 differential expression analysis of RNA sequencing data using R and Bioconductor. Nat Protoc. 2013;8(9):1765-

49586.

496 22. Robinson MD, McCarthy DJ, Smyth GK. edgeR: a Bioconductor package for differential

497 expression analysis of digital gene expression data. Bioinformatics. 2010;26(1):139-40.

498 23. Dillies MA, Rau A, Aubert J, Hennequet-Antier C, Jeanmougin M, Servant N, et al. A

499 comprehensive evaluation of normalization methods for Illumina high-throughput RNA sequencing data

500 analysis. Brief Bioinform. 2013;14(6):671-83. 
501

502

503

504

505

506

507

508

509

510

511

512

513

514

515

516

517

518

519

520

521

522

523

524

525

526

527

528

529

530

531

532

533

534

535

536

537

538

539

540

541

542

543

544

545

546

547

548

549

550

551

552

553

554

555

556

557

24. Benjamini Y, Hochberg Y. Controlling the False Discovery Rate: A Practical and Powerful Approach to Multiple Testing. Journal of the Royal Statistical Society Series B (Methodological). 1995;57(1):289-300.

25. Falda M, Toppo S, Pescarolo A, Lavezzo E, Di Camillo B, Facchinetti A, et al. Argot2: a large scale function prediction tool relying on semantic similarity of weighted Gene Ontology terms. BMC Bioinformatics. 2012;13 Suppl 4:S14.

26. $\quad$ Du Z, Zhou X, Ling Y, Zhang Z, Su Z. agriGO: a GO analysis toolkit for the agricultural community. Nucleic Acids Res. 2010;38(Web Server issue):W64-70.

27. Tian T, Liu Y, Yan H, You Q, Yi X, Du Z, et al. agriGO v2.0: a GO analysis toolkit for the agricultural community, 2017 update. Nucleic Acids Res. 2017;45(W1):W122-W9.

28. Pfaffl MW. A new mathematical model for relative quantification in real-time RT-PCR. Nucleic Acids Res. 2001;29(9):e45.

29. Marshall OJ. PerlPrimer: cross-platform, graphical primer design for standard, bisulphite and realtime PCR. Bioinformatics. 2004;20(15):2471-2.

30. Edgar RC. MUSCLE: multiple sequence alignment with high accuracy and high throughput. Nucleic Acids Research. 2004;32(5):1792-7.

31. Kumar S, Stecher G, Li M, Knyaz C, Tamura K. MEGA X: Molecular Evolutionary Genetics Analysis across Computing Platforms. Molecular biology and evolution. 2018;35(6):1547-9.

32. Le SQ, Gascuel O. An improved general amino acid replacement matrix. Molecular biology and evolution. 2008;25(7):1307-20.

33. Dao TT, Linthorst HJ, Verpoorte R. Chalcone synthase and its functions in plant resistance. Phytochem Rev. 2011;10(3):397-412.

34. Ilyas M, Rasheed A, Mahmood T. Functional characterization of germin and germin-like protein genes in various plant species using transgenic approaches. Biotechnology Letters. 2016;38(9):1405-21.

$35 . \quad$ De Lorenzo G, Ferrari S. Polygalacturonase-inhibiting proteins in defense against phytopathogenic fungi. Current opinion in plant biology. 2002;5(4):295-9.

36. Miedes E, Lorences EP. The implication of xyloglucan endotransglucosylase/hydrolase (XTHs) in tomato fruit infection by Penicillium expansum Link. A. Journal of agricultural and food chemistry. 2007;55(22):9021-6.

37. Zhang X-C, Millet YA, Cheng Z, Bush J, Ausubel FM. Jasmonate signalling in Arabidopsis involves SGT1b-HSP70-HSP90 chaperone complexes. Nature Plants. 2015;1:15049.

38. Takahashi A, Casais C, Ichimura K, Shirasu K. HSP90 interacts with RAR1 and SGT1 and is essential for RPS2-mediated disease resistance in Arabidopsis. Proceedings of the National Academy of Sciences of the United States of America. 2003;100(20):11777-82.

39 Hubert DA, Tornero P, Belkhadir Y, Krishna P, Takahashi A, Shirasu K, et al. Cytosolic HSP90 associates with and modulates the Arabidopsis RPM1 disease resistance protein. EMBO J. 2003;22(21):5679-89. 40. Pieterse CMJ, Leon-Reyes A, Van der Ent S, Van Wees SCM. Networking by small-molecule hormones in plant immunity. Nature Chemical Biology. 2009;5(5):308-16.

41. Mathys J, De Cremer K, Timmermans P, Van Kerkhove S, Lievens B, Vanhaecke M, et al. Genome-wide characterization of ISR induced in Arabidopsis thaliana by Trichoderma hamatum T382 against Botrytis cinerea infection. Frontiers in Plant Science. 2012;3:108.

42. Salas-Marina MA, Silva-Flores MA, Uresti-Rivera EE, Castro-Longoria E, Herrera-Estrella A, Casas-Flores S. Colonization of Arabidopsis roots by Trichoderma atroviride promotes growth and enhances systemic disease resistance through jasmonic acid/ethylene and salicylic acid pathways. European Journal of Plant Pathology. 2011;131(1):15-26.

43. Dixon RA. Natural products and plant disease resistance. Nature. 2001;411(6839):843-7.

44. Treutter D. Significance of flavonoids in plant resistance: a review. Environmental Chemistry Letters. 2006;4(3):147-57.

45. Boachon B, Gamir J, Pastor V, Erb M, Dean JV, Flors V, et al. Role of two UDP-

Glycosyltransferases from the L group of arabidopsis in resistance against Pseudomonas syringae. European journal of plant pathology. 2014;139(4):707-20.

46. Cheng P, Gedling CR, Patil G, Vuong TD, Shannon JG, Dorrance AE, et al. Genetic mapping and haplotype analysis of a locus for quantitative resistance to Fusarium graminearum in soybean accession PI 567516C. Theoretical and applied genetics. 2017;130(5):999-1010.

47. Zimmermann G, Bäumlein H, Mock H-P, Himmelbach A, Schweizer P. The multigene family encoding germin-like proteins of barley. Regulation and function in basal host resistance. Plant Physiology. 2006;142(1):181-92. 
558 48. Dunwell JM, Gibbings JG, Mahmood T, Saqlan Naqvi SM. Germin and Germin-like Proteins:

559 Evolution, Structure, and Function. Critical Reviews in Plant Sciences. 2008;27(5):342-75.

$56049 . \quad$ Livingstone DM, Hampton JL, Phipps PM, Grabau EA. Enhancing resistance to Sclerotinia minor

561 in peanut by expressing a barley oxalate oxidase gene. Plant Physiology. 2005;137(4):1354-62.

$56250 . \quad$ Liu F, Wang M, Wen J, Yi B, Shen J, Ma C, et al. Overexpression of barley oxalate oxidase gene

563 induces partial leaf resistance to Sclerotinia sclerotiorum in transgenic oilseed rape. Plant Pathology.

564 2015;64(6):1407-16.

565 51. Pritsch C, Muehlbauer GJ, Bushnell WR, Somers DA, Vance CP. Fungal development and

566 induction of defense response genes during early infection of wheat spikes by Fusarium graminearum.

567 Molecular Plant-Microbe Interactions. 2000;13(2):159-69.

$568 \quad 52 . \quad$ Venisse J-S, Malnoy M, Faize M, Paulin J-P, Brisset M-N. Modulation of defense responses of

569 Malus spp. during compatible and incompatible interactions with Erwinia amylovora. Molecular Plant-Microbe

570 Interactions. 2002;15(12):1204-12.

$57153 . \quad \quad$ Nakagawa T, Kaku H, Shimoda Y, Sugiyama A, Shimamura M, Takanashi K, et al. From defense

572 to symbiosis: limited alterations in the kinase domain of LysM receptor-like kinases are crucial for evolution of

573 legume-Rhizobium symbiosis. The Plant Journal. 2011;65(2):169-80.

574 54. Brotman Y, Landau U, Cuadros-Inostroza Á, Takayuki T, Fernie AR, Chet I, et al. Trichoderma-

575 Plant Root Colonization: Escaping Early Plant Defense Responses and Activation of the Antioxidant Machinery

576 for Saline Stress Tolerance. PLoS Pathog. 2013;9(3):e1003221.

$577 \quad 55 . \quad$ Vos CMF, De Cremer K, Cammue BPA, De Coninck B. The toolbox of Trichoderma spp. in the

578 biocontrol of Botrytis cinerea disease. Molecular Plant Pathology. 2015;16(4):400-12.

$57956 . \quad$ De Palma M, Salzano M, Villano C, Aversano R, Lorito M, Ruocco M, et al. Transcriptome

580 reprogramming, epigenetic modifications and alternative splicing orchestrate the tomato root response to the

581 beneficial fungus Trichoderma harzianum. Horticulture research. 2019;6(1):5.

$58257 . \quad$ Ho C-L, Tan Y-C, Yeoh K-A, Ghazali A-K, Yee W-Y, Hoh C-C. De novo transcriptome analyses

583 of host-fungal interactions in oil palm (Elaeis guineensis Jacq.). BMC genomics. 2016;17(1):66.

$58458 . \quad$ Yasui Y, Hirakawa H, Oikawa T, Toyoshima M, Matsuzaki C, Ueno M, et al. Draft genome

585 sequence of an inbred line of Chenopodium quinoa an allotetraploid crop with great environmental adaptability

586

587 and outstanding nutritional properties. DNA Research. 2016:dsw037. 
Table 1. RNA-seq summary of read numbers mapped to two quinoa reference genomes

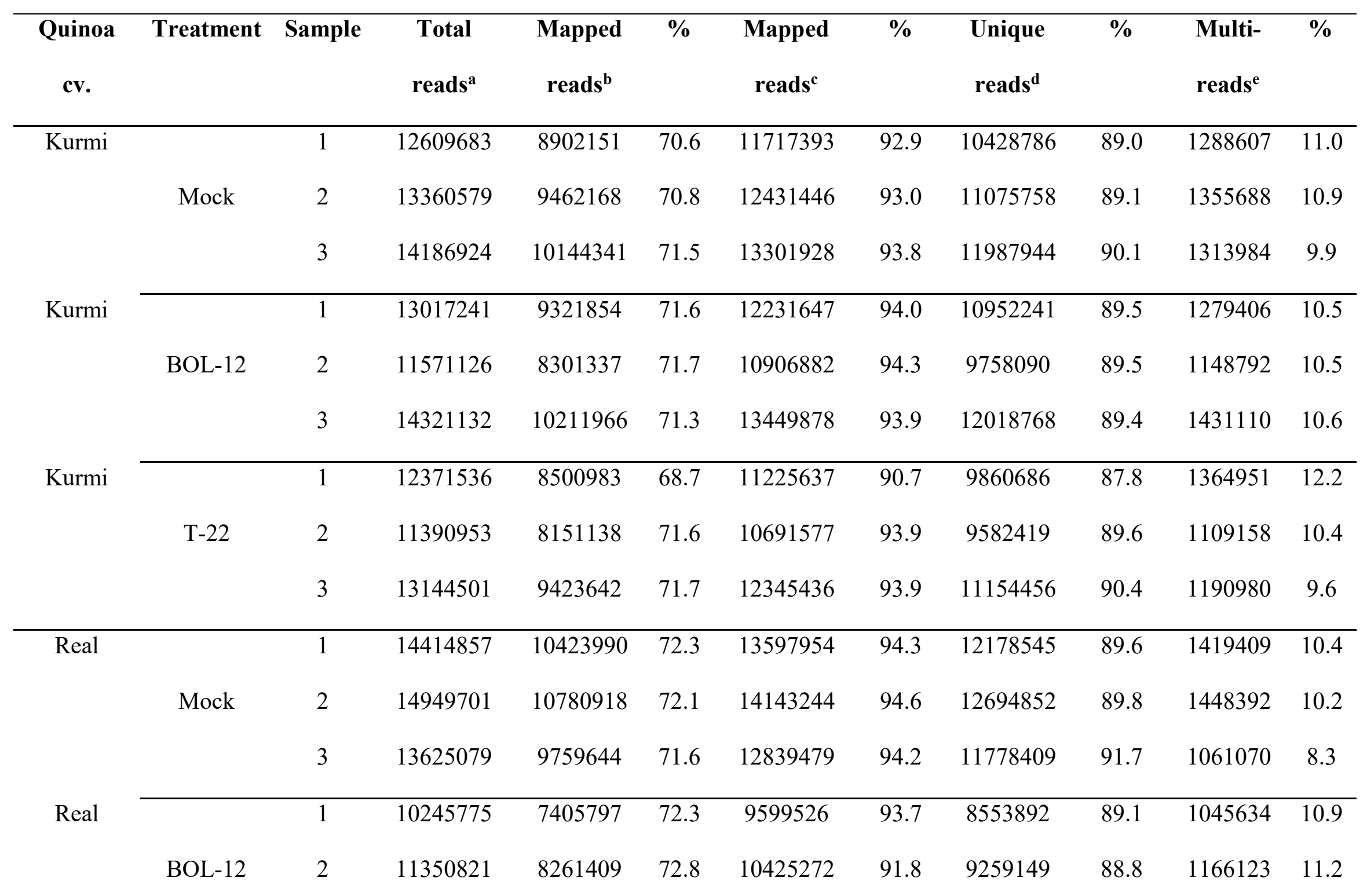




\begin{tabular}{|c|c|c|c|c|c|c|c|c|c|c|c|}
\hline & & 3 & 12542586 & 9091486 & 72.5 & 11767298 & 93.8 & 10725657 & 91.1 & 1041641 & 8.9 \\
\hline \multirow[t]{3}{*}{ Real } & & 1 & 23140059 & 17009224 & 73.5 & 21733959 & 93.9 & 19385551 & 89.2 & 2348408 & 10.8 \\
\hline & $\mathrm{T}-22$ & 2 & 14568308 & 10646741 & 73.1 & 13743816 & 94.3 & 12645961 & 92.0 & 1097855 & 8.0 \\
\hline & & 3 & 11039194 & 8047239 & 72.9 & 10305738 & 93.4 & 9304963 & 90.3 & 1000775 & 9.7 \\
\hline
\end{tabular}

${ }^{\text {a }}$ Total reads that passed the quality control per biological replicate in each treatment

${ }^{\mathrm{b}}$ Average between right and left reads mapped with Tophat2 to the inbred Kd quinoa genome (58).

${ }^{\mathrm{c}}$ Average between right and left reads mapped with Tophat2 to the QQ74 coastal quinoa genome (20).

${ }^{\mathrm{d}}$ Unique reads mapped to the QQ74 coastal quinoa genome.

e Reads mapped to multiple positions 
Table 2. Differentially expressed genes in quinoa roots treated with Trichoderma

\begin{tabular}{|c|c|c|c|c|c|c|}
\hline Quinoa & Experiment & Induced & Repressed & Total & Ind/Repr & Genes evaluated $^{\mathrm{a}}$ \\
\hline Kurmi & BOL-12 vs. mock-treated & 158 & 38 & 196 & 4.2 & 25273 \\
\hline Kurmi & T22 vs. mock-treated & 1417 & 1727 & 3144 & 0.8 & 25379 \\
\hline Real & BOL-12 vs. mock-treated & 277 & 76 & 353 & 3.6 & 30108 \\
\hline Real & T22 vs. mock-treated & 1170 & 139 & 1309 & 8.4 & 30745 \\
\hline
\end{tabular}


Table 3. Quinoa genes differentially expressed in both Kurmi and Real in response to both Trichoderma strains

\begin{tabular}{|c|c|c|c|c|c|c|c|c|}
\hline $\begin{array}{l}\text { Quinoa gene } \\
\text { abbreviation }\end{array}$ & Quinoa gene code ${ }^{a}$ & Gene name & Araport Code ${ }^{b}$ & $\begin{array}{l}\text { Quinoa } \\
\text { protein } \\
\text { length }\end{array}$ & $\begin{array}{l}\text { Alignment } \\
\text { length }\end{array}$ & $\begin{array}{l}\text { Identity } \\
(\%)\end{array}$ & e-value & $\begin{array}{l}\text { GO Cellular } \\
\text { component }\end{array}$ \\
\hline CqXTH6A & AUR62024859 & Xyloglucan endotransglucosylase/hydrolase 6 & AT4G25810.1 & 285 & 284 & 70,1 & $3 \mathrm{E}-154$ & apoplast \\
\hline CqXТН6B & AUR62024861 & Xyloglucan endotransglucosylase/hydrolase 6 & AT4G25810.1 & 286 & 284 & 71,5 & $1 \mathrm{E}-151$ & apoplast \\
\hline EXL4 & AUR62018945 & Protein Exordium-like 4 & AT4G08950.1 & 311 & 298 & 67,5 & 4E-143 & cell wall \\
\hline CqPGIPA & AUR62012077 & Polygalacturonase inhibitor protein & AT5G06860.1 & 311 & 311 & 48,6 & $6 \mathrm{E}-82$ & cell wall \\
\hline$C q P G I P B$ & AUR62024339 & Polygalacturonase inhibitor protein & AT3G12145.1 & 333 & 329 & 44,4 & $3 \mathrm{E}-80$ & cell wall \\
\hline CqChit1 & AUR62021382 & $\begin{array}{l}\text { Glycosyl hydrolase with chitinase insertion domain-containing } \\
\text { protein }\end{array}$ & AT4G19810.2 & 364 & 368 & 47,0 & $3 \mathrm{E}-113$ & $\begin{array}{l}\text { extracellular } \\
\text { region }\end{array}$ \\
\hline CYP707A1 & AUR62010485 & Abscisic acid 8'-hydroxylase 1 & AT4G19230.1 & 450 & 465 & 74,2 & $0 \mathrm{E}+00$ & plasmodesmata \\
\hline$P U B 27$ & AUR62013534 & U-box domain-containing protein 27 & AT5G64660.1 & 392 & 424 & 40,3 & $4 \mathrm{E}-87$ & plasmodesmata \\
\hline CqEP3.3 & AUR62031316 & Basic endochitinase $\mathrm{C}$, homolog of carrot EP3-3 & AT3G54420.1 & 242 & 232 & 62,9 & $1 \mathrm{E}-104$ & $\begin{array}{l}\text { plasma } \\
\text { membrane }\end{array}$ \\
\hline$N N$ & AUR62029900 & Protein of unknown function & AT1G68390.1 & 286 & 216 & 60,2 & $1 \mathrm{E}-96$ & $\begin{array}{l}\text { plasma } \\
\text { membrane }\end{array}$ \\
\hline AUR62005356 & AUR62005356 & Transmembrane protein & AT1G23830.1 & 253 & 138 & 39,1 & $3 \mathrm{E}-22$ & $\begin{array}{l}\text { plasma } \\
\text { membrane }\end{array}$ \\
\hline SD25 & AUR62006585 & $\begin{array}{l}\text { G-type lectin S-receptor-like serine/threonine-protein kinase } \\
\text { SD2-5 }\end{array}$ & AT4G32300.1 & 831 & 789 & 35,1 & $4 \mathrm{E}-124$ & $\begin{array}{l}\text { plasma } \\
\text { membrane }\end{array}$ \\
\hline Atlg35710 & AUR62039001 & Probable leucine-rich repeat receptor-like protein kinase & AT1G35710.1 & 478 & 451 & 37,3 & 5E-66 & $\begin{array}{l}\text { plasma } \\
\text { membrane }\end{array}$ \\
\hline CqHSP83a & AUR62031424 & Heat-shock protein 83 & AT5G52640.1 & 579 & 443 & 92,6 & $0 \mathrm{E}+00$ & cytoplasm \\
\hline
\end{tabular}




\begin{tabular}{|c|c|c|c|c|c|c|c|c|}
\hline CqHSP83b & AUR62021118 & Heat-shock protein 83 -like & AT5G52640.1 & 703 & 700 & 93,1 & $0 \mathrm{E}+00$ & cytoplasm \\
\hline CXE2 & AUR62014711 & Probable carboxylesterase 2 & AT1G47480.1 & 304 & 301 & 50,5 & 7E-109 & cytosol \\
\hline AUR62011434 & AUR62011434 & Protein of unknown function & AT2G26530.1 & 269 & 184 & 33,7 & $2 \mathrm{E}-16$ & intracellular \\
\hline CIGRI & AUR62001765 & Chitin-inducible GRAS family transcription factor & AT2G29060.2 & 690 & 626 & 43,3 & $1 \mathrm{E}-165$ & nucleus \\
\hline ERF071 & AUR62025525 & Ethylene-responsive transcription factor ERF071 & AT2G47520.1 & 249 & 217 & 42,9 & $3 \mathrm{E}-44$ & nucleus \\
\hline CqWRKY33* & AUR62006298 & WRKY33 transcription factor & AT2G38470.1 & 454 & 487 & 46,8 & $7 \mathrm{E}-116$ & nucleus \\
\hline
\end{tabular}

All genes commonly differentially expressed in all plant-Trichoderma combinations were induced.

${ }^{a}$ Genes annotated in the Quinoa QQ74 genome (Jarvis et al., 2017) curated with information from their closest ortholog in $A$.

thaliana

${ }^{\mathrm{b}}$ Gene codes from the Arabidopsis Information portal Araport.

* CqWRKY33 was included in the list of genes because significant difference respective to the control was confirmed by qRT-PCR (Fig. 5) 
bioRxiv preprint doi: https://doi.org/10.1101/2021.04.14.439738; this version posted April 15, 2021. The copyright holder for this preprint (which was not certified by peer review) is the author/funder, who has granted bioRxiv a license to display the preprint in perpetuity. It is made available under aCC-BY-NC 4.0 International license. 